\title{
ESCOLA SEM PARTIDO E AS IMPLICACOEESPARA A DEMOCRATIZAÇÃO DA EDUCAÇÃO
}

\author{
SCHOOL WITHOUT PARTY AND IMPLICATIONS FOR THE \\ DEMOCRATIZATION OF EDUCATION \\ ESCUELA SIN PARTIDO E LAS IMPLICACIONES PARA LA \\ DEMOCRATIZACIÓN DE LA EDUCACIÓN
}

Paula Valim de Lima

paulavdelima@hotmail.com

Vera Maria Vidal Peroni

veraperoni@gmail.com

\begin{abstract}
REVISTA PEDAGÓGICA
Revista do Programa de Pós-graduação em Educação da Unochapecó | ISSN 1984-1566 Universidade Comunitária da Região de Chapecó | Chapecó-SC, Brasil Como referenciar este artigo: LIMA, P. V.; PERONI, V. M. V. Escola Sem Partido e as implicações para a democratização da educação. Revista Pedagógica, Chapecó, v. 20, n. 44, p. 121-136, mai./ago. DOI: http://dx.doi.org/10.22196/rp.v20i44.4009
\end{abstract}

RESUMO: $O$ presente artigo se propõe a discutir as implicações do Escola sem Partido (ESP) para a democratização da educação pública brasileira-O ESP é um movimento em defesa de uma lei que, sob a prerrogativa de combater a doutrinação política e ideológica nas escolas, cria mecanismos de censura aos professores aliados a uma determinada proposta de educação e de sociedade. A principal esfera de atuação do movimento é a proposição de projetos de lei nas Câmaras Municipais, Assembleias Legislativas e no Congresso Nacional, propondo a instituição do chamado "Programa Escola Sem Partido". A partir da análise é possível perceber que o ESP é um movimento essencialmente contraditório à democraciabrasileirae à democratização da educação e busca, portanto, romper com a possibilidade de construção de uma educação emancipadora, vinculada aos valores sociais, políticos e culturais existentes na diversidade e que possibilitem uma prática democrática na escola.

Palavras-chave:Escola sem Partido. Educação pública. Democratização da Educação

ABSTRACT: This paper proposes to discuss the implications of the School without a Party (ESP) for the democratization of Brazilian public education. The ESP is a movement in defense of a law that, under the prerogative to combat political and ideological indoctrination in schools, creates censorship mechanisms for teachers allied to a specific proposal of education and society. The main sphere of activity of the movement is the proposition of bills in the Municipal Councils, Legislative Assemblies and in the National Congress, proposing the institution of the so-called "Sem School Program". From the analysis it is possible to perceive that ESP is a movement that is essentially contradictory to Brazilian democracy and the democratization of education and seeks to break with the possibility of building an emancipatory education, linked to the social, political and cultural values that exist in diversity and That make possible a democratic practice in school.

Keywords: School without Party. Public education. Democratization of Education

RESUMEN: El presente artículo se propone discutir las implicaciones de Escuela sin Partido (ESP) para la democratización de la educación pública brasileña. El ESP es un movimiento en defensa de una ley que, bajo la prerrogativa de combatir el adoctrinamiento político e ideológico en las escuelas, crea mecanismos de censura a los profesores aliados a una determinada propuesta de educación y de sociedad. La principal esfera de actuación del movimiento es la proposición de proyectos de ley en las Cámaras Municipales, Asambleas Legislativas y en el Congreso Nacional, proponiendo la institución del llamado "Programa Escuela sin Partido". A partir del análisis es posible percibir que el ESP es un movimiento esencialmente contradictorio a la democracia brasileña ya la democratización de la educación y busca, por lo tanto, romper con la posibilidad de construcción de una educación emancipadora, vinculada a los valores sociales, políticos y culturales existentes en la diversidad y que posibiliten una práctica democrática en la escuela.

Palabras clave: Escuela sin Partido. Educación pública. Democratización de la Educación 


\section{INTRODUÇÃO}

O presente artigo é um recorte de uma pesquisa que teve como objetivo identificar e analisar as implicações do ESP para a democratização da educação pública brasileira. A escrita deste trabalho se insere em um contexto bastante crítico no cenário políticobrasileiro. Desde o golpe parlamentar de 2015, que afastou a presidenta democraticamente eleita, o novo governo vem aplicando no país um programa de expressão neoliberal, com a retirada de direitos, redução sistemática de políticas sociais e esvaziamento do Estado.Ainda que os governos anteriores tenham assumido uma postura de tentiva de conciliação entre a classe trabalhadorae o próprio capital, a última década foi de alguns avanços para os trabalhadores, com os programas de transferência de renda, inclusão social e erradicação da pobreza (CHAUI, 2016). A partir da ocasião do golpe, a agenda governamental se voltou prioritariamente aos interesses dos empresários e dos bancose, por conta disso, as diversas ações propostas pelo governo ilegítimo atacam os direitos duramente conquistados pelos trabalhadores ao longo de toda uma história de luta e resistência.

Dentro deste contexto - e entendendo a necessidade de engajamento social e político por parte dos professores e professoras como sujeitos da educação - faz-se necessário discutir sobre uma temática que tem se apresentado como uma ameaça à educação brasileira e ao trabalho docente, que ganhou força no último período junto a tantas outras medidas de retrocesso: o Escola sem Partido (ESP), justamente conhecido como Lei da Mordaça. A escolha do objeto da pesquisa se deu a partir da necessidade da investigação sobre a proposta do Escola sem Partido, articulada a uma leitura social mais ampla, contextualizada histórica e politicamente.

A perspectiva teórico-metodológica que embasa esta pesquisa passa pela compreensão de que a política educacional é parte constitutiva das mudanças sociais e econômicas em um processo de relação em que Estado e sociedade civil são partes constitutivas do movimento de correlação de forças (GRAMSCI,1989) entre sujeitos (THOMPSON, 1981), perpassados por projetos societários distintos. Nesse sentido, trabalhei com a categoria analítica "conteúdo da proposta”, sendo esta expressão utilizada para compreender qual a concepção, qual a lógica que se insere na educação pública por meio das diferentes propostas apresentadas para a educação por diferentes sujeitos, interferindo tanto na escola quanto na formulação da política educacional.

Ainda, se coloca a necessidade de analisar o objeto da pesquisa "em suas múltiplas relações, enquanto movimento, que se materializa na realidade social com muitas contradições, através de sujeitos com projetos societários distintos" (PERONI, 2015, p. 16-17). É preciso examinar o objeto de estudo considerando o espaço e o contexto histórico que o produziram, partindo do pressuposto de que 
1 http://www.escolasempartido.org/quem-somos. Acesso em 25 mar. 2017.

2 https://www.noindoctrination.org. Endereço eletrônico indisponível desde 2016. a política educacional não é, simplesmente, determinada pelas mudanças que estão ocorrendo na redefinição do papel do Estado, mas é parte constitutiva dessas mudanças.

Portanto, é importante analisar a política educacional atual no contexto da redefinição do papel do Estado, que por sua vez está inserida em um movimento maior do capitalismo no qual, na tentativa de superar sua crise, foram estabelecidas, como estratégias principais, neoliberalismo, globalização, reestruturação produtiva e Terceira Via (PERONI, 2010, p. 541).

Trata-se de uma pesquisa documental, entendendo que a análise de documentos contribui por considerar que estes "expressam não apenas diretrizes para a educação, mas articulam interesses, projetam políticas, produzem intervenções sociais" (EVANGELISTA, 2008, p. 1-2), manifestando uma concepção de mundo, de sociedade, de educação. Assim, é necessário "compreender a posição desses documentos em relação a sua história, a história do seu tema e a história da produção da sua empiria" (EVANGELISTA, 2008, p. 6), devendo ser entendidos dentro de um contexto histórico pois somente ali farão sentido.

\section{ESCOLA SEM PARTIDO}

O movimento Escola Sem Partido (ESP) surgiu em 2004, através de um site na internet, descrevendo-se como uma "iniciativa conjunta de estudantes e pais preocupados com o grau de contaminação político-ideológica das escolas brasileiras, em todos os níveis: do ensino básico ao

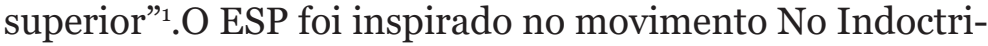
nation, uma iniciativa norte-americana que se constituiu como um fórum on-line ${ }^{2}$ de denúncias anônimas de professores que estariam inserindo agendas políticas em sala de aula, na tentativa de "doutrinar" os alunos a uma maneira específica de pensar.

Apresentando-se sob a forma de movimento independente e sem qualquer espécie de vinculação política, ideológica ou partidária, o EscolaSemPartido.org nasce como um espaço de divulgação de testemunhos de vítimas de doutrinação nas escolas. O movimento, que não recebia muita atenção nem por parte dos opositores, "permaneceu na obscuridade até o início da década de 2010, quando passou a ser uma voz frequente nos debates sobre educação no Brasil" (MIGUEL, 2016, p. 595). É neste período que começam a aparecer alguns sinais da ascensão do movimento, conforme Ximenes (2016).

O movimento amplia sua atuação com o passar dos anos, sempre visando o combate à doutrinação e o abuso da liberdade de ensinar por parte dos professores, assumindo uma agenda articulada em diferentes esferas, incluindo a criação da Associação Escola sem Partido, pessoa 
3 Disponível em http://www.escolasempartido.org/vestibular-categoria/579-escola-sem-partido-representa-contra-presidente-do-inep-por-crime-de-abuso-de-autoridade-e-improbidade-administrativa. Acesso em 5 mai. 2017.

4 Programa Escola sem Partido (PESP) refere-se ao proposto nos Projetos de Lei.

5 http://www.programaescolasempartido. org/. Acesso em 2 abr. 2017 jurídica de direito privado sem fins lucrativos, que serviria para mover ações jurídicas em casos pertinentes. Vale destacar que, com isso, a primeira ação judicial do movimento foi movida contra o INEP (Instituto Nacional de Pesquisas Educacionais Anísio Teixeira), em janeiro de 2016, por considerar crime de abuso de autoridade a atribuição de nota zero às redações que desrespeitassem os direitos humanos, conforme consta no Edital do Enem $2015^{3}$.

A principal e mais expressiva frente de atuação do movimento é a do campo legislativo, também a mais grave para a educação pública brasileira. A disputa dentro da legislação brasileira se iniciou em 2013, quando o movimento formulou Anteprojetos de Lei a partir de suas propostas, que serviriam como base para proposições nas instâncias parlamentares, nos âmbitos municipal, estadual e federal. Assim, em maio de 2014, foi apresentado à Assembleia Legislativa do Rio de Janeiro o primeiro projeto do ESP, que propunha a criação, no âmbito do sistema estadual de ensino, do Programa Escola Sem Partido 4 (PESP). Desde então, diversos outros parlamentares repetiram a atitude e apresentaram às Câmaras Municipais e Assembleias Legislativas de diferentes regiões do Brasil, bem como ao Congresso Nacional, projetos muito semelhantes e com poucas variações - em geral de adequação ao âmbito da proposta - sempre baseados nos anteprojetos disponibilizados pelo movimento em endereço eletrônico ${ }^{5}$.

Para analisar o conteúdo da proposta apresentada pelo ESP é necessário conhecer efetivamente do que se trata, quais seus argumentos e sua matéria, de modo geral. Assim, a análise que segue se baseia principalmente no texto do Anteprojeto de Lei Federal,elaborado pelo movimento. Isso porque dezenas de projetos foram elaborados a partir dos diferentes anteprojetos, portanto, estes documentos são os que melhor expressam os pensamentos e reivindicações do movimento ESP. O conteúdo de outros materiais e documentos publicados pelo movimento também aparecem ao longo do texto, para contribuir com elementos a análise.

\section{A ESCOLA DO ESCOLA SEM PARTIDO}

Para analisar o conteúdo da proposta é precisoconsiderar a relação entre projeto de educação e projeto de sociedade, apesar da tentativa de se "difundir a ideia de uma educação neutra, supostamente desvinculada de um projeto de sociedade e de interesses de diferentes ordens" (GIROTTO, 2016, p. 70).Se, por um lado, podemos considerar que não se trata essencialmentede um projeto de educação, mas de escolarização, já que a tese central do ESP é que o professor não é educador e sua tarefa, portanto, limita-se à instrução dos estudantes (PENNA, 2016), por outro lado, precisamos reconhecer que,ao negar a tarefa educativa da escola e a destituir de qualquer caráter educacional, o ESP assume um pressuposto educativo - conservador, incapaz 
6 http://veja.abril.com.br/brasil/pais-aprovam-as-escolas-ruins/. Acesso em o8 mai. 2017

7 Levantamento realizado em og de maio de 2017. Não foram considerados depoimentos encaminhados ou publicados originalmente em outros sites ou fóruns. de intervir no mundo e que Abrucio (2016) preferiu chamar de "escola sem sentido".

Assim, é preciso retomar os principais elementos que compõem o corpo da proposta do movimento, que se atravessam de diferentes formas, mas que tem sentidos próprios entre si. Para iniciara conversa, o coração do ESP: o combate à doutrinação política e ideológica. De início, o movimento elege a doutrinação como o grande malda educação, a qual afirmam ser conhecida por experiência de todos que passaram pelo sistema de ensino nos últimos 20 ou 30 anos - vale destacar: justamente o período de abertura democrática pós-ditadura no Brasil.O principal argumento sobre a existência de doutrinação política e ideológica nas escolas baseia-senos resultados de uma pesquisa de opinião encomendada pela revista Veja ao Instituto CNT/ Sensus em $2008^{6}$, cujo resultado é bastante controverso.

Em um texto publicado no site da Nova Escola, Ratier (2016) concorda que a doutrinação é uma prática inadequada nas escolas, mas questiona a amplitude do problema, afirmando que não há estudos sistemáticos sobre o tema e faz a análise de que a preocupação dos professores em "formar cidadãos" é equivocadamente lida como "apenas e tão somente martelar ideias de esquerda na cabeça dos estudantes". Na seção "perguntas frequentes" (FAQ) no site do movimento, alega-se que a esquerda promove

[...] a doutrinação político-ideológica em sala de aula, de forma sistemática e organizada, com apoio teórico (Gramsci, Althusser, Freire, Saviani, etc.), político (governos e partidos de esquerda, PT à frente), burocrático (MEC e secretarias de educação), editorial (indústria do livro didático) e sindical (Disponível em http://www.escolasempartido.org/faq. Acesso em 09 mai. 2017).

Isso se reflete nos depoimentos divulgados no site do movimento, em que 41 relatos denunciam a doutrinação de professores - chamados de comunistas, PTistas, marxistas, esquerdistas, socialistas, entre outras coisas - sobre temasassociados à esquerda, enquanto apenas dois relatos denunciam professores com práticas ou posicionamentos à direita ${ }^{7}$.

De qualquer forma, ainda que a doutrinação seja o foco do movimento, sua definição não é claramente explicitada em nenhum momento, mas ela pode ser compreendida nas minúcias do conteúdo dos materiais elaborados pelo ESP, quando, por exemplo, se define como doutrinadora a prática dos professores de utilizarem-se de sua função docente
[...] para tentar obter adesão dos estudantes a determinadas correntes políticas e ideológicas; e para fazer com que eles adotem padrões de julgamento e de conduta moral especialmente moral sexual - incompatíveis 
com os que lhe são ensinados por seus pais ou responsáveis (Disponível em http://www. programaescolasempartido.org/anteprojeto-estadual/ Acesso em 23 abr. 2017).

O documento "Flagrando o doutrinador", elaborado pelo movimento e disponível em sua página eletrônica, também dá indícios do que seria, então, a doutrinação ideológica:

Você pode estar sendo vítima de doutrinação ideológica quando seu professor:

- se desvia freqüentemente da matéria objeto da disciplina para assuntos relacionados ao noticiário político ou internacional; (Disponível em http://escolasempartido.org/flagrando-o-doutrinador Acesso em 29 ago. 2017)

Isso remeteà ideia de uma escolarização tecnicista e conteúdista, em que professor atua como simples reprodutor de conhecimentos estanques, produzidos em um outro espaço, desconectados da realidade (PENNA, 2016).

Alia-se a isso a ideia de neutralidade proposta pelo movimento, entendida como a negativa da possibilidade de o professor emitir sua opinião sobre os conteúdos que ensina, esvaziando também a possibilidade de interpretação crítica sobre qualquer tema, tornando alienados o trabalho docente e a aprendizagem (XIMENES, 2016).De certo modo, o ESP opera com o antagonismo neutralidade $X$ ideologia, especialmente no que diz respeito às concepções políticas e morais, sem considerar as discussões no campo da educação que há muito chegaram ao lugar-comum de que não existe neutralidade na educação ou educação livre de ideologia.

Após perceber que a defesa de uma educação neutra seria, no mínimo, uma demonstração de enorme ignorância, o movimento Escola Sem Partido passou a advogar em defesa de uma prática pedagógica supostamente plural. Porém, sob o véu da pluralidade declarada o que se observa é a promoção de um perigoso dogmatismo conservador (CARA, 2016, p. 45).

Acompanhando a falsa noção de neutralidade, entra um aspecto chave da leitura da proposta do movimento: a censura. Isso principalmente a partir da interpretação do movimento de que os professores não tem assegurado o direito da liberdade de expressão e que esta seria incompatível com a liberdade de ensinar, uma vez que a liberdade de expressão daria ao professor o direito de dizer qualquer coisa sobre qualquer assunto e que este não é o caso, pois os professores tem a obrigação de transmitir aos alunos o conteúdo específico da sua disciplina. É certo que não há uma liberdade absoluta no ensino: 
Há objetivos educacionais, componentes curriculares, deveres funcionais, conhecimentos científicos e contextos específicos que relativizam o exercício de tais liberdades. Muito diferente disso é, entretanto, o cerceamento absoluto e a priori da liberdade [...] (Ximenes, 2016, p. 57).

Nesse sentido Miguel (2016), explica que a liberdade de expressão do professor assume a forma de liberdade de cátedra - liberdade para escolher o caminho que julga melhor para a promoção da formação de seus alunos, assim como é garantido como princípio da educação nacional o pluralismo não só de ideias, mas de concepções pedagógicas. Portanto, "a liberdade de expressão do professor não é uma irresponsabilidade; ao contrário, é uma necessidade de sua responsabilidade profissional" (MIGUEL, 2016, p. 614).

Sobre isso, Girotto (2016) considera que a interdição dos discursos dos professores é fruto da tentativa de controlar o que fazem cotidianamente nas suas salas de aula e de redução do trabalho docente à sua dimensão técnica, pois

Ao definir os conteúdos, conceitos, metodologias e ações que os docentes e discentes devem desenvolver [...], difundem-se visões de mundo, conhecimentos, valores e perspecivas que representam os interesses de determinados grupos econômicos, em detrimento da pluralidade que deve estar na base de toda prática educativa (GIROTTO, 2016, p. 72).

Fica evidente que a disputa do ESP se trava no campo curricular e atravessa todos os espaços da educação. Isso porque o movimento pretende direcionar o currículo, selecionando os temas que podem ou não ser apresentados nas salas de aula e, com isso, neutralizar o trabalho do professor.

Isso se aplica na relação entre as famílias e as escolas. O movimento ESP traz consigo a condição da soberania da família sobre a escola em tudo que se relaciona às questões morais e ideológicas, o que é incluído nos PLs como princípio da educação nacional e é objeto dos dois PLs de Erivelton Santana, fundamentado na ideia da "intocabilidade da família, como sujeito coletivo com direitos próprios, irredutíveis aos de seus integrantes" (MIGUEL, 2016, p. 605). Essa noção, da primazia da família sobre a escola, se vincula à imposição das vontades privadas contra o interesse comum e é daí que vem a necessidade do ESP de garantir uma educação escolar ideológica e moralmente neutra, que não intervenha em assuntos que, do seu ponto de vista, devem ser restritos ao âmbito privado.

Este aspecto da proposta tem como base de seu argumento o que consta na Convenção Americana de Direitos Humanos (CADH), Artigo 12 e especialmente o inciso 4, da qual o Brasil é signatário. Segundo Penna (2016), entretanto, a interpretação do ESP sobre o tema é equivocada 
pois entende que não se pode sequer dialogar sobre esses assuntos com crianças e jovens nas escolas. Mas "essa é uma proibição completamente absurda, pois impediria a construção dos valores necessários a uma convicência democrática e o combate a toda forma de valores preconceituosos" (PENNA, 2016, p. 52). Há de considerar, ainda, que a própria família pode ser um lugar de opressão e violência e não se pode abster de proteger, sempre, os direitos individuais de seus integrantes, estando entre eles o direito "de ter acesso a uma pluralidade de visões de mundo, a fim de ampliar a possibilidade de produção autônoma de suas próprias ideias" (MIGUEL, 2016, p. 605).

O direito de escolha dos pais, portanto, não pode ser interpretado como um direito absoluto que se sobreponha aos objetivos educacionais públicos definidos nas normas educacionais, nos projetos pedagógicos e na abordagem didática dos docentes. Dizer isso, por outro lado, não esvazia o direito dos pais, já que esses continuarão atuando nas demais dimensões da educação [não-formal e informal] sobre as quais é praticamente nula a intervenção direta dos agentes estatais (XIMENES, 2016, p. 56).

Além disso, essa noção - da primazia da família sobre a escola - recai em uma ideia de propriedade dos filhos sobre os pais, o que originou o slogan "Meus filhos, minhas regras" que veio a se tornar lema do ESP, repetido em intervenções públicas e como hashtag em redes sociais.

Como um contraponto a esta ideia, Souza e Gonçalves (2016) afirmam que
A soberania da instituição familiar sobre o processo de ensino se contrapõe ao caráter plural da legislação brasileira que reconhece o papel da família como importante agência formadora do indivíduo, mas indica a escola como espaço público de acolhimento da diver- sidade e formação para o exercício da cidada- nia (SOUZA; GONÇALVES, 2016, p. 140).

Ao mesmo tempo, cabe destacar que o princípio da gestão democrática na educação pressupõe o esforço de aproximar as famílias do cotidiano da escola, incentivando a ampla participação nos diferentes espaços.

Sendo a escola um espaço heterogêneo, não há como se estabelecer um ambiente de pluralidade sem que haja disposição dos sujeitos que a compõem para experimentar a contradição de ideias e pensamentos. A Nota Técnica $\mathrm{n}^{0}$ 2/2017/PFDC, de 15 de março de 2017, da Procuradoria Federal dos Direitos dos Cidadãos do Ministério Público Federal, que trata sobre o documento intitulado "Modelo de notificação extrajudical", expõe argumentos sobre o assunto: 
Ora, uma vez que há mais de uma concepção de moral familiar e considerando que a educação formal (o ensino escolar), como serviço prestado, é, por sua própria natureza, indivisível, não parece razoável supor que cada pai de aluno possa exercer a função unilateral de censor de conteúdos pedagógicos, pela simples razão de que se todos resolvessem fazer o mesmo, o próprio ato do aprendizado coletivo estaria impossibilitado pelo esvaziamento de qualquer conteúdo controverso. Dito de outro modo: a pretensão invocada (submissão de um serviço coletivo e indivisível à vontade unilateral individual do autor da notificação) não se constitui como direito subjetivo porque não pode ser logicamente universalizada, em razão da natureza indivisível do serviço prestado (Nota Técnica n ${ }^{0}$ 2/2017/PFDC, 2017).

Além disso, na Nota Técnica 1/2016 do mesmo órgão, a procuradora Deborah Duprat alegou que o projeto "confunde a educação escolar com aquela fornecida pelos pais e, com isso, os espaços público e privado”.

Ainda que se pretenda aplicar esse pressuposto sobre todos os assuntos pautados em sala de aula, fica evidente que a maior preocupação em relação à educação moral das crianças reside no que os conservadores vieram a chamar de "ideologia de gênero",não a toa que existem artigos em todos os PLs ou trechos nas justificações que pautam a moral sexual. O próprio Modelo de notificação extrajudicial também tem este foco. Segundo Coelho (2016), essa nomenclatura surge à margem dos estudos de gênero, tendo aparecido pela primeira vez em 1998, na Conferência Episcopal do Peru, que formulou uma nota intitulada La ideologia de género: sus peligros y alcances.

O documento de 16 páginas despertou o apoio de toda a Igreja Católica e inclusive de setores evangélicos em diferentes países e também no Brasil, de forma que estes passaram a se referir aos estudos de gênero como "ideologia de gênero". Tal termo, atualmente consagrado, utiliza-se de argumentos conservadores que constroem "fatos" sobre o que é natural à luz de suas verdades e difundem pânico moral de gênero. Ainda, o termo ideologia de gênero, veemente utilizado em disputas políticas que supostamente defendem a família natural, é aplicado com a intenção de promover a manutenção dos interesses dos segmentos católicos e evangélicos no cenário político de nosso país (COELHO, 2016, p. 1).

A necessidade de combater a "ideologia de gênero" parte do pressuposto que dialogar sobre as diferentes possibilidades de expressão do gênero e da sexualidade não somente abre espaço, como incentiva à subversão dos arranjos familiares tradicionais considerados pelos conservadores como "naturais, de origem divina e indispensáveis 
à reprodução da vida social" (MIGUEL, 2016, p. 598). Limitar essa discussão, entretanto, acarreta no impedimento do combate ao preconceito e a intolerância e da disseminação de valores de igualdade e respeito às diferenças e, ainda, da própria reflexão dos indivíduos sobre sua própria sexualidade, reforçando o ideal da heteronormatividade, sem espaço para diferentes expressões de gênero e sexualidade.

O impedimento de tratar dos temas gênero e sexualidade é prejudicial para os espaços educativos e, ainda, contrário aos princípios do pluralismo de ideias e do respeito à liberdade e apreço à tolerância, previstos na LDB/96. A Nota Técnica 2/2017, já citada anteriormente, expressa o mesmo entendimento:

Ou seja, em vez de, no âmbito de uma discussão democrática, conduzida no próprio ambiente escolar, pleitear que as questões relacionadas à sexualidade, orientação sexual e identidade de gênero sejam tratadas de forma objetiva e pluralista, [...] pretende unilateralmente censurar qualquer referência ("ainda que de forma ilustrativa ou informativa") a respeito de tais temas, ignorando até mesmo o óbvio interesse público na difusão de informações relacionadas à saúde sexual e reprodutiva de adolescentes e na promoção da igualdade de gênero e orientação sexual no ambiente escolar (Nota Técnica $\mathrm{n}^{\mathrm{O}} 2 / 2017$ / PFDC, 2017).

\subsection{A Escola Sem Partido no cenário atual}

De certo modo, o ESP se mostra coerente e em conssonância com diversos outros projetos que vêm sendo apresentados no parlamento brasileiro neste último período, em especial a Reforma do Ensino Médio (MP 746/2016), recentemente aprovada. Entre outras coisas, a Reforma reestrutura a última etapa da educação básica,ampliandosua carga horária mínima anual e redefinindoseu currículo, flexibilizando a oferta de disciplinas como arte e educação física, enquanto prioriza o português e a matemática, entre outras mudanças. Vale ressaltar que as disciplinas de ciências humanas, cuja carga horária sofreu uma redução expressiva, têm sido os principais alvos de ataques dos defensores do Escola Sem Partido (GIROTTO, 2016).

Ramos e Frigotto (2016) fazem a análise de que a MP dificulta o acesso ao patrimônio científico, cultural, social, ético e político pela maioria dos jovens da classe trabalhadora, promovendo um acesso desigual ao conhecimento e à cultura, deacordo com a classe social. Os autores argumentam ainda que o conjunto de mudanças propostas pela medida acabamrestringindo as escolhas de acesso ao ensino superior, além de dificultar a inserção dos jovens no mercado de trabalho, condenando-os ao trabalho de pouco valor econômico (RAMOS; FRIGOTTO, 2016). De 
modo geral, a Reforma do Ensino Médio acarreta no "aumento da relação entre educação e mercado de trabalho, reforçando assim a concepção tecnicista que tem definido a escola de pensamento único nas últimas décadas no Brasil" (GIROTTO, 2016, p. 72).

Nesse sentido, o cerne da questão, em que Reforma do Ensino Médio e Escola sem Partido se encontram, é a consolidação da escola como um espaço que sirva

[...] ao propósito de não só fornecer os conhecimentos e o pessoal necessário à máquina produtiva em expansão do sistema do capital, como também gerar e transmitir valores que legitimam os interesses dominantes, como se não pudesse haver nenhuma alternativa à gestão da sociedade (MÉSZÁROS, 2008, p. 35).

É daí que aparece a necessidade, por parte do sistema capitalista e em prol da sua manutenção, de "internalização" de determinados valores por parte dos indivíduos, de modo que estes adotem pra si as metas de reprodução do sistema. De certa forma, é a isso que tem servido a educação escolar nos últimos séculos, cumprindo o papel de "produzir tanta conformidade ou 'consenso' quanto for capaz, a partir de dentro e por meio dos seus próprios limites institucionalizados e legalmente sancionados" (MÉSZÁROS, 2008, p. 45).

A educação, nesse sentido,se apresenta como um campo importante na correlação de forças por projetos societários distintos, porque ela pode subsidiar, a um só tempo, duas coisas opostas: a transgressão à ordem social vigente, ou a sua manutenção, especialmente neste período particular de crise do capitalismo.

E aqui temos a crise como um elemento importante para esta análise, uma vez que as diferentes estratégias propostas para a sua superação interferem fortemente na política educacional. Isso porque

\begin{abstract}
A forma capitalista de resolver os problemas, sempre a favor do capital, também se apresenta à educação, mediante a imposição da lógica do capital ao setor [...]. Dessa forma, a questão central em disputa é a determinação do Estado em favor do capital ou dos trabalhadores (COMERLATTO, 2014, p. 2).
\end{abstract}

Enquanto de um lado há o entendimento de que a crise atual nada mais é do que uma crise cíclica do capitalismo, por ser este um sistema "essencialmente contraditório e, por isso, produtor estrutural de crises periódicas" (COMERLATTO, 2013, p. 26), por outro lado, o diagnóstico neoliberal, compartilhado pela Terceira Via, considera que o causador da crise é o Estado, 
demandas da população por políticas sociais, o que provocou a crise fiscal, quanto porque, ao regulamentar a economia, atrapalhou o livre andamento do mercado (PERONI, 2006, p. 13).

Desse modo, a partir desse diagnóstico de que a crise está no Estado, e não no capital, a principal estratégia para sua superação estáem redefinir o papel do Estado, esvaziando-o de sua função de promotor e executor de políticas sociais. Nesse sentido o setor privado, como propõe o Noeoliberalismo, ou terceiro setor, pela proposição da Terceira Via, assumem determinadas funções para superar as falhas do Estado, impondo a lógica do setor privado, e portanto, do mercado, inclusive ao que se mantém público.

O mesmo pode ser verificado no campo da educação. Peroni (2003) evidencia as transformações neste campo, quando alega que o eixo das políticas educativas que, especialmente após o período de abertura democrática, era centrado principalmente na democratização da ecola como processo de democratização da sociedade, passa a assumir, a partir dos anos 1990, uma lógica mercantil.

Destaca-se que a reivindicação pela democratização da educação é uma bandeira dos movimentos sociais de educação há longo tempo, que se intensificou no período após a ditadura, resultando na aprovação do princípio de gestão democrática na educação, no artigo 206 na CF/88, sendo entendida como a participação dos diferentes setores da comunidade escolar nos processos de decisão da escola.

Nesse sentido, pode-se dizer que a gestão democrática implica na participação. A participação, por sua vez, implica que os sujeitos envolvidos no processo

percebam-se como agentes e não expectadores do processo, em que a autonomia possa ser exercida com sua real finalidade, ou seja, elaboração conjunta de políticas educacionais que visem melhores condições para uma formação de qualidade das crianças e dos jovens que fazem parte do processo escolar (CAETANO, 2013, p. 76).

A gestão democrática na educação, portanto,se constitui como uma oportunidade de experimentação de práticas democráticas desde a escola, sendo"o início do aprendizado da democracia e define-se como a mediação para a realização de uma sociedade livre" (CAETANO, 2013).

Essa questão remete ao antagonismo democracia $\mathrm{X}$ capitalismo, de que trata Ellen Wood (2011) quando aponta que a democracia é uma condição contraditória ao capitalismo, o que se apresenta também no campo da educação:

O capitalismo é estruturalmente antiético à democracia [...] porque a condição insuperável de existência do capitalismo é o fato de a mais básica das condições de vida [...] ter 
de se submeter aos ditames da acumulação do capital e às "leis" do mercado. Isso quer dizer que o capitalismo coloca necessariamente mais e mais esferas da vida fora do alcance da responsabilidade democrática (WOOD, 2011, p. 8).

Assim, estebelecem-se, grosso modo, dois projetos educativos distintos, certamente vinculados a projetos societários também distintos: um que pretende romper com a lógica do mercado e do capital no campo da educação; e outro que quer reforçar essa lógica em seu interior.

Uma vez que o ESP se mostra comprometido com os interesses do capital, é possível verificar que o combate à doutrinação política e ideológica proposto pelo movimento nada mais é do que o combate auma educaçãocomprometida com a democracia, com a emancipação humana e com a formação de sujeitos conscientes do seu papel social. O objetivo final do movimento é romper com a possibilidade de construção de uma educação vinculada às questões e valores sociais, políticos e culturais existentes na diversidade, e que possibilitam o exercício de uma prática democrática na escola a partir de mecanismos de intervenção e participação coletiva estabelecidos através do princípio da gestão democrática, substituindo-a por uma educação sem espaço de participação, que promova a preservação acrítica do sistema capitalista e, consequentemente, das suas desigualdades.

\section{CONSIDERAÇÕES FINAIS}

Finalmente, pode-se dizer que o projeto educativo defendido pelo ESP implica na educação nacional em três dimensões: a) do trabalho docente, que passa a ser censurado e constantemente vigiado, perdendo sua dimensão social de formação para a cidadania, para a diversidade e para o convívio social; b) do currículo escolar, que também se esvazia do sentido social, ficando reduzido a uma lista de conteúdos e conhecimentos, supostamente neutros, desvinculados da realidade social, política, econômica e cultural em que se insere - e nesse sentido é que surgem as propostas de alteração da LDB e dos PCNs; e c) dafunção da escola na constução de valores democráticos e exercício da cidadania e da criticidade, reforçando a expressão "Escola sem Sentido", proposta por Abrucio (2016) e incorporada ao título deste trabalho.

É bastante evidente, a partir da análise, que o ESP é um movimento essencialmente contraditório à democracia e à democratização da educação, pois esgota a possibilidade de diálogo - tanto dentro da escola, como fora dela, quando silenciam os sujeitos da educação na elaboração de políticas educativas. Além disso, a proposta do movimento impede a expressão da diversidade, negando o caráter heterogêneo do espaço escolar, do qual fazem parte sujeitos 
oriundos de diferentes espaços, com diferentes formas de ler o mundo e hierarquiza os sujeitos, de acordo com sua função ou lugar na escola, em especial no que diz respeito à relação professor/estudante e família/professor.

Ao longo de toda a discussão sobre o ESP, fica latente uma premissa que deve ser central no entendimento dessa questão: a relação entre projeto de educação e projeto de sociedade. Falar em democratização da educação é, portanto, falar em democratização da sociedade, justamente porque a escola é um espaço social de formação de princípios e valores para além dela mesma.

Nesse sentido, o ESP impede a construção de valores democráticos no espaço escolar, certamente porque representa interesses de outras ordens, em especial os interesses do capital, em promover uma educação que dê conta de produzir conformidades e consensos (MÉSZÁROS, 2008) que o favoreçam, por reconhecer que a educação democrática, emancipatória, crítica e questionadora é uma ferramenta potente para a trangressão à ordem social vigente.

A preocupação do movimento em ocupar todos os espaços necessários para controlar o conteúdo da educação - currículos, projetos político-pedagógicos, materiais didáticos, seleção de professores, entre outras - é o que torna possível determinar os pensamentos, visões de mundo, ideias e valores possíveis de estarem na escola e aqueles que devem ser proibidos. A escola que decorrerá disso "trará riscos ao processo formativo dos estudantes, por ser medíocre, cerceadora e incapaz de preparar os alunos para a vida" (CARA, 2016, p. 44).

Concluo esta escrita convidando a todos a combaterem o projeto autoritário e anti-democrático do Escola sem Partido, fortalecendo os movimentos de educadores e estudantes que se colocam em oposição ao ESP. É preciso resistir à tentativa de silenciamento dos sujeitos da educação, para defender um projeto de educação pública, gratuita, democrática, laica e de qualidade, comprometida com a emancipação humana.

\section{REFERÊNCIAS}

ABRUCIO, Fernando. Contra escola sem sentido. In: A ideologia do movimento Escola sem Partido: $20 \mathrm{au}-$ tores desmontam o discurso. Ação Educativa Assessoria, Pesquisa e Informação (Org). São Paulo: Ação Educativa, 2016. p. 59-64.

CAETANO, Maria Raquel. Relações entre o público e o privado: a gestão pedagógica da educação no Programa Circuito Campeão do Instituto Ayrton Senna (2007-2010). (Tese de Doutorado). UFRGS. Faculdade de Educação, PPGEDU. Porto Alegre, RS, 2013.

CARA, Daniel. O Programa "Escola sem Partido" quer uma escola sem educação. In:A ideologia do movimento 
Escola sem Partido: 20 autores desmontam o discurso. Ação Educativa Assessoria, Pesquisa e Informação (Org). São Paulo: Ação Educativa, 2016. p. 43-48.

CHAUI, Marilena. A nova classe trabalhadora brasileira e a ascensão do conservadorismo. In: CLETO, Murilo; DORIA, Kim; JINKINGS, Ivana (Org.). Por que gritamos golpe? Para entender o impeachment e a crise política no Brasil. São Paulo: Boitempo, 2016, p. 15-22

COELHO, F.M.F. Ideologia de Gênero: origens e consagração no Brasil. In:II Simpósio Internacional da ABHR / XV Simpósio Nacional da ABHR / II Simpósio Sul da ABHR, Florianópolis, Santa Catarina. 2010.

COMERLATTO, Luciani Paz. A gestão da educação no contexto da sociedade capitalista: a parceria público privado. (Tese de doutorado). Programa de Pós-Graduação em Educação. Faculdade de educação da UFRGS, 2013.

A crise estrutural do capitalismo e a gestão da educação. In: XANPED SUL, 2014, Florianópolis. Políticas Públicas e Gestão Educacional, 2014. v. 10. p. 1-19.

EVANGELISTA, Olinda. Apontamentos para o trabalho com documentos de política educacional. 2008.

GIROTTO, Eduardo. Um ponto na rede: o "Escola sem Partido" no contexto da escola do pensamento único. In: A ideologia do movimento Escola sem Partido: 20 autores desmontam o discurso. Ação Educativa Assessoria, Pesquisa e Informação (Org). São Paulo: Ação Educativa, 2016.p. 69-76.

MÉSZÁROS, István. A educação para além do capital. São Paulo: Boi Tempo Editorial, 2006 (Mundo do Trabalho).

MIGUEL, Luis Felipe. Da “doutrinação marxista" à "ideologia de gênero" - Escola sem Partido e as leis da mordaça no parlamento brasileiro. Revista Direito e Práxis, Vol. 07, n.15, 2016, p. 590-621.

PENNA, Fernando. Programa "Escola Sem Partido": Uma ameaça à educação emancipadora. In. In: MONTEIRO, A. M. F. da C., GABRIEL, C. T. \& MARTINS, M. L. B. Narrativas do Rio de Janeiro nas aulas de história. Rio de Janeiro: Mauad, 2016, p. 43-58.

O ódio aos professores. In: A ideologia do mo-

vimento Escola sem Partido: 20 autores desmontam o discurso. Ação Educativa Assessoria, Pesquisa e Informação (Org). São Paulo: Ação Educativa, 2016.p. 93-100.

PERONI, Vera M. Vidal et al. (Orgs.). Dilemas da educação brasileira em tempos de globalização 
neoliberal: entre o público e o privado. Porto Alegre, UFRGS, 2006

PERONI, Vera M. Vidal.A parceria entre sistemas públicos de educação e o Instituto Ayrton Senna: Implicações para o trabalho docente.In: XVIII Seminário Internacional de formação de Professores para o MERCOSUL/Cone Sul, Florianópolis Santa Catarina, 2010. . (org.). Redefinições das fronteiras entre o público e o privado: implicações para a democratização da educação. Brasília: Liber Livro, 2013

RAMOS, Marisa Nogueira. FRIGOTTO, Gaudêncio. Medida Provisória 746/2016: a contra-reforma do ensino médio do golpe de estado de 31 de agosto de 2016. In: Revista HISTEDBR On-line, Campinas, no 70, p. 30-48, dez. 2016.

SOUZA, Ana Lucia. GONÇALVES, Ednéia. Reeducação das relações raciais e ESP. In: A ideologia do movimento Escola sem Partido: 20 autores desmontam o discurso. Ação Educativa Assessoria, Pesquisa e Informação (Org). São Paulo: Ação Educativa, 2016.p. 137-148

THOMPSON, E. P. A miséria da teoria ou um planetário de erros. Rio de Janeiro: Zahar, 1981.

WOOD, Ellen Meiksins. Democracia contra capitalismo: a renovação do materialismo histórico. Tradução de Paulo Cezar Castanheira. São Paulo: Boitempo Editora, 2006.

XIMENES, Salomão. O que o direito à educação tem a dizer sobre o Escola sem Partido. In: A ideologia do movimento Escola sem Partido: 20 autores desmontam o discurso. Ação Educativa Assessoria, Pesquisa e Informação (Org). São Paulo: Ação Educativa, 2016.p.49-58.

Recebido em: 30/09/2017 Aprovado em: 08/08/2018 Publicado em: 31/o8/2018 